\section{EMITTER CHEMICAL IONIZATION MASS SPECTROMETRY OF KANAMYCINS}

Sir :

Emitter chemical ionization mass spectrometry (Emitter CIMS) developed by HUNT et al. is a new technique for analysis of involatile and thermally unstable compounds ${ }^{1)}$. This method has been performed by use of activated field desorption (FD) emitter as a solid probe under CI condition. However, no systematic investigation of this technique has been reported, whereas, interest in the mass spectrometric analysis of aminoglycoside antibiotics is enhanced considerably due to the fact that amino sugar sequencing of this type of antibiotics except for gentamicins has not reproduciblly been determined by EI, $\mathrm{CI}$ and even $\mathrm{FDMS}^{2,3)}$. The present investigation was undertaken to explore the utility of this technique for structural characterization of aminoglycosides, particularly kanamycins, which afforded no reproducible sequence ions in the FD mass spectra ${ }^{4)}$.

All emitter CI mass spectra were recorded on a Shimadzu LKB 9000A mass spectrometer, equipped with a CI source. $2 \sim 10 \mu \mathrm{g}$ of sample dissolved in water was placed on the carbon emitter consisted of tungsten wire $(10 \mu \mathrm{m})$. The emitter current was increased at a rate of $0.2 \mathrm{mAs}^{-1}$. Optimum emitter currents were $24 \sim 35 \mathrm{~mA}$. The source temperature was $250^{\circ} \mathrm{C}$. The emission current was $120 \mu \mathrm{A}$ and electron energy was 150 $\mathrm{eV}$. Both isobutane and ammonia reagent gas pressures were maintained at 0.1 Torr.

Isobutane and ammonia emitter $\mathrm{CI}$ mass spectra of intact kanamycin A (1) are compared in Fig. 1. Both emitter CI mass spectra afforded unequivocally protonated molecular ion $\left(\mathrm{MH}^{+}\right)$at $m / z$ 485. Besides, molecular ioncluster in the isobutane emitter $\mathrm{CI}$ mass spectrum is weakly observed at $\mathrm{m} / \mathrm{z} 523\left(\mathrm{M} \cdot \mathrm{C}_{3} \mathrm{H}_{3}{ }^{+}\right), 525$ $\left(\mathrm{M} \cdot \mathrm{C}_{3} \mathrm{H}_{5}{ }^{+}\right), 527\left(\mathrm{M} \cdot \mathrm{C}_{3} \mathrm{H}_{7}{ }^{+}\right)$and $541\left(\mathrm{M} \cdot \mathrm{C}_{4} \mathrm{H}_{9}{ }^{+}\right)$. These ions indicate precisely the molecular weight of 1 . In both isobutane and ammonia emitter CI mass spectra, major fragmentations are virtually identical. Cleavage of the glycosidic linkages results in the formation of five series of sequence ions $(a \sim e)$ marked on Fig. 1. The ions $a$ and/or $d$ at $m / z 162$ arise from protonation of one of the glycosidic oxygen atoms, followed by elimination of pseudodisaccharide portion. The losses of kanosamine and/or 6'-amino-6'-deoxyglucose unit from $\mathrm{MH}^{+}$give ions $b$ and/or $c$ at $m / z 324$. The ion $e$ at $m / z 163$ represents a further loss of monosaccharide unit from the ions $b$ and/or $c$.

Then, emitter CI mass spectra of kanamycin B (2) and $\mathrm{C}$ (3) were determined. In addition to $\mathrm{MH}^{+}$ions, sequence ions $(a \sim e)$ are also observed with both isobutane and ammonia as the reagent gases. The principal fragmentation pattern and the $m / z$ values of the above ions are summarized in Fig. 2. These are the ions formed by reproducible fragmentation process at glycosidic linkages. Moreover, the shifting technique using ammonia- $d_{3}$ as the reagent gas which is characteristic of CIMS could be successfully employed to characterize the diagnostic ions ${ }^{5)}$.

The preliminary results indicate that Emitter CIMS can be adopted for the structural analysis of other involatile and thermally unstable compounds. These results will be reported elsewhere.

Fig. 1. Emitter CI mass spectra of kanamycin A (1) using (A) isobutane and (B) ammonia.

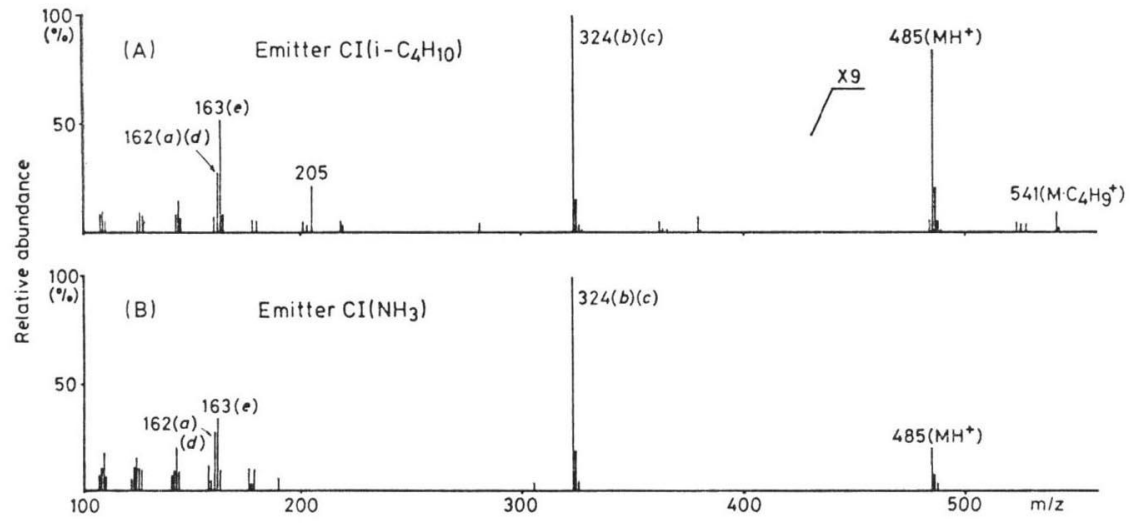


Fig. 2. Major fragmentations and the resulting sequence ions observed in the emitter $\mathrm{CI}\left(i-\mathrm{C}_{4} \mathrm{H}_{10} /\right.$ $\mathrm{NH}_{3}$ ) mass spectra of $\mathbf{1}, \mathbf{2}$ and $\mathbf{3}$.

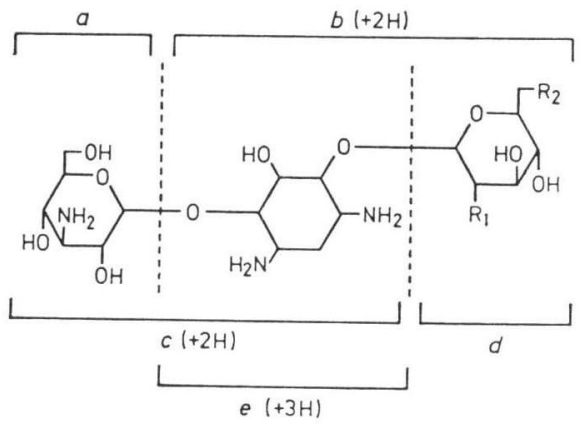

\begin{tabular}{l|llllll}
\hline & $\mathrm{MH}^{+}$ & $a$ & $b$ & $c$ & $d$ & $e$ \\
\hline $\begin{array}{l}\text { Kanamycin } \mathrm{A}(\mathbf{1}) \\
\mathrm{R}_{1}=\mathrm{OH}, \mathrm{R}_{2}=\mathrm{NH}_{2}\end{array}$ & 485 & 162 & 324 & 324 & 162 & 163 \\
\hline $\begin{array}{l}\text { Kanamycin B (2) } \\
\mathrm{R}_{1}=\mathrm{NH}_{2}, \mathrm{R}_{2}=\mathrm{NH}_{2}\end{array}$ & 484 & 162 & 323 & 324 & 161 & 163 \\
\hline $\begin{array}{l}\mathrm{Kanamycin}_{2} \mathrm{C}(\mathbf{3}) \\
\mathrm{R}_{1}=\mathrm{NH}_{2}, \mathrm{R}_{2}=\mathrm{OH}\end{array}$ & 485 & 162 & 324 & 324 & 162 & 163 \\
\hline
\end{tabular}

\section{Acknowledgement}

The authors wish to thank Dr. TeIICHIRo Ito, Research Laboratory, Meiji Seika Co. Ltd., for providing sample of kanamycin B.

\author{
NAOHITO TAKEDA \\ MASAYo UMEMURA \\ KeN-ICHI HARADA \\ MaKoto Suzuki \\ AKIra Tatematsu
}

Faculty of Pharmacy, Meijo University Tempaku-ku, Nagoya, 468, Japan

(Received February 21, 1981)

\section{References}

1) Hunt, D. F.; J. Shabanowitz, F. K. Botz \& D. A. BRENT: Chemical ionization mass spectrometry of salts and thermally labile organics with field desorption emitters as solids probes. Anal. Chem. 49: 1160 1163, 1977

2) Parfitt, R. T.; D. E. Games, M. Rossiter, M. S. Rogers \& A. Weston: Chemical ionization and field desorption mass spectrometry of gentamicins. Biomed. Mass Spectrom. 3: 232 234, 1976

3) Rinehart, K. L., Jr.; J. C. СoоK, Jr., K. H. MAURER \& U. RAPP: Field desorption mass spectra of antibiotics. J. Antibiotics 27: 1 13, 1974

4) Suzuki, M.: Application of mass spectrometry for the screening of microbial metabolites. Ferment. \& Ind. 38: 197 215, 1980 (In Japanese)

5) Suzuki, M.; K. Harada, N. Takeda \& A. TAtematsu: Chemical ionization mass spectrometry of macrolide antibiotics. II. Heterocycles $15: 1123 \sim 1130,1981$ 